\title{
GÊNERO, TRABALHO E BENEFÍCIO DE PRESTAÇÃO CONTINUADA - CONSIDERAÇÕES SOBRE AS INTERFACES ENTRE AS POLÍTICAS DE PREVIDÊNCIA E ASSISTÊNCIA SOCIAL*
}

\author{
Marcia Cardoso Araújo \\ Andréa Gama
}

\section{Introdução}

Esse capítulo apresenta os resultados da pesquisa sobre a trajetória de trabalho dos requerentes do Benefício de Prestação Continuada (BPC), sob a perspectiva de gênero, realizada em 2018, em duas agências da Previdência Social, no município de Niterói, estado do Rio de Janeiro. Tínhamos como pressuposto que os (as) requerentes do BPC possuíam uma trajetória de trabalho, contudo, em virtude da precarização das condições e relações de trabalho não conseguiam alcançar os requisitos para acessar os benefícios previdenciários, recorrendo ao benefício assistencial para acesso à renda, em virtude do processo de envelhecimento e doença/deficiência. Ademais, buscamos analisar as semelhanças e diferenças na conformação desse processo, considerando as relações de gênero. A incorporação dessa perspectiva contribui para desvelar os constrangimentos de gênero no trabalho que conformarão desigualdades no acesso às políticas de previdência e assistência social no país. Tais processos inerentes ao trabalho terão repercussões importantes para o acesso aos benefícios previdenciários e assistenciais. Nesse sentido, indagamos: de que forma as desigualdades de gênero no trabalho se mostram no âmbito das políticas previdenciárias e assistenciais? Qual é a influência do trabalho reprodutivo na trajetória de trabalho desses requerentes, considerando, ainda, que possam haver diferenças nesse processo quando se trata de idosas (os) e pessoas com deficiências? Essas distinções provocam demandas diferenciadas nas políticas de previdência e assistência social? Essas são questões que pretendemos responder nesse artigo.

Para a consecução dos objetivos da pesquisa, realizamos 40 (quarenta) entrevistas semiestruturadas com requerentes do benefício assistencial, englobando tanto o segmento das pessoas idosas quanto o das pessoas com deficiên-

${ }^{*}$ DOI - 10.29388/978-65-86678-20-8-0-f.163-180 
cia, sendo 10 (dez) entrevistas com homens e 10 (dez) entrevistas com mulheres, por segmento social. Por envolver entrevista com seres humanos, o projeto de pesquisa foi submetido e aprovado pelo Comitê de Ética em Pesquisa da UERJ, sob o número 2.444.947.

A organização do artigo está estruturada em três itens, a saber: 1 - Breves considerações sobre trabalho e gênero; 2 - Perfil dos requerentes do BPC; 3 - Gênero e trajetória de trabalho dos requerentes do benefício assistencial.

\section{1 - Breves considerações sobre gênero e trabalho}

A discussão sobre Gênero, Trabalho e Benefício de Prestação Continuada é dotada de relevância social na contemporaneidade, considerando as desigualdades assentadas na divisão sexual do trabalho e o aumento da precariedade das condições e relações de trabalho que se materializam na perda e restrição de direitos trabalhistas e sociais com repercussões diferenciadas para homens e mulheres.

Neste contexto, discutir as relações sociais de gênero é fundamental, porque temos como pano de fundo um cenário em que as mulheres sofrem mais com os desdobramentos da precariedade do mercado de trabalho e, simultaneamente, com a centralidade do papel que exercem frente às demandas do âmbito doméstico, agravadas pela insuficiência de políticas públicos para que elas possam permanecer no mercado de trabalho em condições de igualdade com os homens.

A importância social do BPC nessa conjuntura está na garantia de um salário-mínimo de benefício mensal à pessoa com deficiência e ao idoso que comprove não possuir meios de prover à própria manutenção ou de tê-la provida por sua família, independentemente de contribuição prévia, na medida em que muitos(as) trabalhadores(as) não possuem condições de manter vínculo com a Previdência Social, em virtude da precarização das relações e condições de trabalho. A criação do BPC representou uma importante inovação na seguridade social brasileira por ser independente de contribuição prévia, inaugurando na proteção social brasileira o acesso à renda às pessoas idosas e/ou com deficiência, independente de inserção pretérita no mercado de trabalho ou de contrapartidas pecuniárias. Dessa forma, muitos trabalhadores que se encontram sem a proteção da Previdência Social, por ser esta uma política de caráter contributivo, recorrem ao benefício assistencial para viabilizar acesso à renda, especialmente, aqueles que não possuem contribuições para o INSS ou até para 
aqueles que tenham a dita qualidade de segurado do INSS, mas que não conseguiram acessar o auxílio-doença ou aposentadoria. No entanto, diferentemente dos benefícios previdenciários que incidem sobre o(a) trabalhador(a) individual em sua trajetória de trabalho e contribuição, o BPC depende da renda familiar, adicionando à trajetória de trabalho, a variável "família" no acesso ao benefício, evidenciando um traço característico da política de assistência social brasileira. A pesquisa buscou compreender este movimento, a fim de analisar a trajetória de trabalho dos(as) requerentes do benefício assistencial, identificando semelhanças e diferenças entre homens e mulheres, de ambos os segmentos sociais.

O mercado de trabalho brasileiro, desde a década de 1990, passou por transformações em virtude dos processos de reestruturação produtiva, financeirização dos mercados e desmonte do Estado Social pelo ideário neoliberal, tal como analisado por Harvey (1993), Iamamoto (2007)e entre outros. Tal nível de desestruturação do mercado de trabalho brasileiro, historicamente caracterizado por uma forte segmentação, representou uma ininterrupta perda de direitos sociais para a classe trabalhadora, a fim de atender às exigências de grandes instituições financeiras, de caráter nacional/internacional, sob a égide do ideário neoliberal. Nessa conjuntura, entretanto, homens e mulheres apresentavam traços particulares no processo de precarização das condições e relações de trabalho, fortemente influenciada pela divisão sexual e racial do trabalho.

A abordagem que aqui assumimos é a da divisão social do trabalho em termos de relações de classes, gênero e raça/etnia, permitindo desenvolver uma conceituação ampla do trabalho, compreendido como atividade remunerada/assalariada e atividade desenvolvida na esfera doméstica. Essa abordagem permite uma análise das interdependências que marcam o processo histórico de separação/articulação da produção e da reprodução social e a transformação permanente do trabalho assalariado e da família. Isso exige uma nova compreensão das relações com o trabalho - e das formas que essas relações assumem, dos modos de organização, seu papel e suas funções - bem como das diferentes instituições ligadas à reprodução social dos indivíduos. (Gama, 2014)

Entendemos a divisão sexual do trabalho, como:

A divisão sexual do trabalho é a forma de divisão do trabalho social decorrente das relações sociais entre os sexos; mais do que isso é um fator prioritário para a sobrevivência da relação social entre os sexos. Essa forma é modulada histórica e socialmente e tem como características a designação prioritária dos homens à esfera produtiva e das mulheres à esfera reprodutiva e, simultaneamente, a apropriação pelos homens das fun- 
ções com maior valor social adicionado (políticos, religiosos, militares, etc). (Hirata e Kergoat, 2007, p. 596).

Apesar de tal designação às mulheres, crescentemente, ocupam os espaços públicos, em especial, o mercado de trabalho. Contudo, não deixaram de ocupar o papel central de cuidados no âmbito familiar, sendo esta uma das principais diferenças entre homens e mulheres que repercute diretamente não apenas na sua atuação no âmbito público, como também no interior das famílias.

Estudos afirmam que o trabalho reprodutivo condiciona a inserção das mulheres no mercado de trabalho e que elas recebem as demandas acerca do trabalho reprodutivo fazendo com que o trabalho produtivo seja tratado como secundário. (Bandeira e Preturlan, 2016).

Compreendemos que o trabalho reprodutivo é aquele que envolve a realização de atividades de cuidado com familiares, crianças, idosos, pessoas doentes ou com deficiências, bem como daquelas atividades como lavar e passar roupa, cozinhar, limpar a casa, limpar o jardim, lavar louças, entre outras, realizadas no espaço da própria residência e sem qualquer tipo de remuneração. (Pinheiro, 2016)

Homens e mulheres se deparam com questões pertinentes ao mercado de trabalho brasileiro que são comuns ao conjunto da classe trabalhadora, como o desemprego, a flexibilização das relações e condições de trabalho, a informalidade, o aumento da jornada de trabalho, entre outros. No entanto, tais características não repercutem de forma igual entre os gêneros e as classes.

Bruschini (2007) aponta que a inserção das mulheres no mercado de trabalho brasileiro tem sido caracterizada através do tempo pela precariedade, que tem atingido uma importante parcela de trabalhadoras. Em 2005, nada menos que $33 \%$ da força de trabalho feminina ou 12 milhões de mulheres situavam-se em nichos precários, ou de menor qualidade, no mercado de trabalho, seja como trabalhadoras domésticas (mais de 6,2 milhões), seja realizando atividades não remuneradas (3,3 milhões) ou trabalhos na produção para o consumo próprio ou do grupo familiar, (2,7 milhões). A autora ainda sinaliza que um dos exemplos dessas modalidades de inserção da mulher no mercado de trabalho tem sido o emprego doméstico que se apresenta como um espaço de destaque para as inserções das mulheres, desde 1970. (Bruschini, 2007)

De acordo com Hirata (2002), o aumento do emprego feminino remunerado acompanhado pela sua precarização e vulnerabilidade crescentes é um dos paradoxos da globalização. Além disso, as desigualdades de salário e a precarização das condições de trabalho não diminuíram ao longo das décadas, mui- 
to pelo contrário, as mulheres são mais afetadas pelo aumento da precarização das condições de trabalho, especialmente, porque a divisão do trabalho doméstico não se modificou, mesmo com o envolvimento crescente nas responsabilidades profissionais por parte das mulheres.

No caso brasileiro, isso é agravado pelas enormes desigualdades existentes entre as classes sociais, que permitiram que a incorporação maciça de mulheres no mercado de trabalho tivesse sido efetuada sem maiores mudanças no tocante à divisão generificada do trabalho doméstico. As empregadas domésticas são um exército de mulheres pobres e negras, com baixa qualificação, custo baixíssimo e representam o maior contingente de trabalhadoras do país. A existência dessas trabalhadoras possibilita que a prestação pelas mulheres dos serviços domésticos não seja interrompida e continue sobre os ombros femininos, mesmo na ausência da mulher/mãe do lar. Tal processo de externalização do trabalho doméstico, no caso brasileiro, também contém o traço da opressão racial.

Estudos revelam, ainda, a maior inserção de mulheres em trabalhos com jornadas reduzidas, o que indica a necessidade de combinar as atividades remuneradas com o trabalho reprodutivo realizado no âmbito doméstico, apontando para uma tendência de feminilização que se dá por conta do crescimento de mulheres nas atividades como: camelôs e vendedoras autônomas, em especial, de cosméticos e de roupas, funções estas consideradas precarizadas, por serem desprotegidas e para atender às necessidades sociais imediatas. Diferentemente dos homens, que ocupam maior espaço em trabalhos formais com jornadas mais longas e fixas, apresentando maior taxa de trabalho no âmbito formal e menor tempo em situação de desemprego. (Araujo e Lombardi, 2013).

O desemprego é mais um fenômeno que evidencia as desigualdades de gênero no mercado de trabalho, porque impacta mais as mulheres ao longo dos anos, agravando os prejuízos em relação ao tempo de contribuição à Previdência Social e de efetivo tempo de trabalho produtivo. Além disso, os dados demonstram que o desemprego entre as mulheres é mais elevado e que estas ainda vivenciam maior tempo na busca por nova ocupação quando comparada aos homens. (Bandeira e Preturlan, 2016).

O que queremos dizer é que, mediante as reflexões teóricas sinalizadas, as mulheres se inserem de maneira subordinada no mundo do trabalho que se beneficia dessa condição social para aumentar a exploração da força de trabalho no seu conjunto. O sobre desemprego feminino alimenta o desemprego masculino, a precarização do trabalho feminino se articula com as novas formas de produção que tendem à redução geral dos salários e à intensificação do trabalho 
em todos os setores econômicos.

Reforçamos nosso entendimento de que são expressivas as desigualdades de inserção no mercado de trabalho entre homens e mulheres, em virtude das características da divisão sexual e racial do trabalho que permeia as relações sociais, tanto no âmbito familiar, quanto no âmbito produtivo representando espaços que se retroalimentam.

A divisão sexual e racial do trabalho não somente condiciona e determina a inserção das mulheres no mercado de trabalho, como também gera uma diferença expressiva entre homens e mulheres na política de Previdência Social, porque impacta diretamente na possibilidade de tempo de contribuição e no alcance ou não dos benefícios previdenciários.

As recentes alterações no mundo do trabalho, associadas ao retrocesso das políticas sociais ensejadas pelo ultraliberalismo, com ênfase nas mudanças na política de Previdência Social, fazem com que muitos trabalhadores(as) busquem a política de assistência social, para ter acesso à renda, por meio do benefício assistencial, em virtude da negação das solicitações de benefícios previdenciários ou da inexistência de contribuições previdenciárias.

Grande parte dos homens e mulheres que buscam o benefício assistencial para acesso à renda, sejam pessoas idosas ou com deficiência, possuem a qualidade de trabalhadores, no entanto, não conseguem manter uma trajetória de trabalho que possibilite a continuidade de vínculo com a política de Previdência Social, em virtude do aumento da precariedade no âmbito do trabalho, como veremos adiante.

Os dados coletados do Anuário Estatístico da Previdência Social (2015), mostram que essas particularidades definem "o lugar" de homens e mulheres no acesso aos benefícios previdenciários. Os homens possuem um lugar de destaque nas aposentadorias por tempo de contribuição, por outro lado, as mulheres ocupam maior espaço nas aposentadorias por idade e/ou como pensionistas. Isto se dá porque elas permanecem menos tempo em condições de trabalho formal, acarretando menor tempo de contribuição e impossibilitando o alcance do tempo mínimo para a aposentadoria por tempo de contribuição que com a atual mudança na legislação previdenciária aumentou para 62 anos de idade para mulheres e manteve 65 anos de idade para os homens. Para ambos o tempo de contribuição permaneceu 15 anos de contribuição e 180 meses de carência para aposentadoria. Os critérios de exigibilidade para acesso à aposentadoria no período da realização da pesquisa eram 60 anos de idade para as mulheres e 65 anos de idade para os homens, além da exigência de 15 anos de contribuição para ambos. Isso torna comum o acesso das mulheres à aposentadoria 
por idade ou como pensionista, por conta das desigualdades de gênero e raça já analisadas.

\section{2 - Perfil dos requerentes do Benefício de Prestação Continuada}

Neste item, abordaremos as características de homens e mulheres de ambos os segmentos sociais que requereram o benefício assistencial, como: faixa etária, escolaridade, rendimentos, renda familiar, recebimento ou não de rendimentos provenientes do Programa Bolsa Família e a qualidade de segurado ou não do INSS.

Cabe destacar que, de acordo com o Anuário Estatístico da Previdência Social de 2017, o BPC está mais concentrado no segmento social das pessoas com deficiência quando comparado ao segmento social dos idosos, respectivamente, 2.525.924 e 2.020.204 benefícios ativos. As regiões do Brasil que concentram maior número de benefícios ativos, são: Nordeste com $36 \%$, Sudeste, com $34 \%$, Sul com $11 \%$, Norte com $10 \%$ e o Centro-Oeste com $9 \%$.

Segundo dados do Ministério da Cidadania (2019), no Estado do Rio de Janeiro, o benefício assistencial é mais concentrado no segmento das pessoas idosas quando comparado ao segmento das pessoas com deficiência, respectivamente, 198.929 e 136.523 beneficiários.

A pesquisa mostrou que a idade das mulheres que requereram o benefício assistencial direcionado para as pessoas idosas variou entre 65 a 69 anos de idade. Não há diferenças significativas no que tange à idade entre homens e mulheres idosos que está concentrada entre 65-66 anos. Este resultado demonstra uma tendência dos(as) entrevistados(as) solicitarem o benefício assistencial no ano em que completaram a idade mínima para requererem o benefício assistencial que é de 65 anos de idade. As mulheres que requereram o BPC para a pessoa com deficiência apresentaram faixas etárias bem diversificadas, não apresentando um padrão específico de idade e nem diferenças entre os gêneros. A maioria $\operatorname{dos}(\mathrm{as})$ que solicitaram o benefício pertenciam a faixa etária acima de 40 anos de idade.

A maior parte das mulheres e dos homens do segmento das pessoas idosas possuem o ensino fundamental. Dois idosos, um homem e uma mulher, se declararam analfabetos. Dentre os entrevistados deste segmento, o número de homens com ensino médio é superior vis-à-vis as mulheres. No segmento das pessoas com deficiência, identificamos que a maioria dos entrevistados de- 
clararam ter o ensino fundamental. Dois homens se declararam analfabetos. Em relação à escolaridade, não houve diferenças significativas entre os dois grupos estudados. Os dados indicam que os requerentes do BPC possuem como tendência uma baixa escolaridade caracterizada pelo fato de em sua maioria, tantos os homens, quanto as mulheres de ambos os segmentos sociais estarem restritos ao ensino fundamental. Além disso, destacamos que quatro entrevistados se declararam analfabetos.

A renda é um aspecto importante nesta análise porque, além de ser um dos indicadores socioeconômicos mais relevantes, trata-se também de uma das condicionalidades para o acesso ao benefício. A maioria de homens e mulheres idosos não possuía nenhuma renda. Em seguida, identificamos que uma parte destes entrevistados declararam ter rendimentos de até 1 salário mínimo relacionados ao Programa Bolsa Família e de pequenos rendimentos de serviços informais que prestam, como: produção e venda de alimentos, serviços de limpeza de terrenos e reciclagem. Nenhum homem idoso declarou renda maior que 1 salário mínimo. Uma idosa declarou ter rendimento familiar por conta do BPC idoso do cônjuge. A única idosa que declarou renda superior a 2 salários-mínimos é pensionista do INSS. A maioria dos requerentes com deficiência também não possui nenhuma renda. Os entrevistados que declararam rendimentos de até 1 salário-mínimo contam com valores do Programa Bolsa Família, doação de familiares e a prestação de serviços informais. Sendo assim, podemos afirmar que não há diferenças significativas entre os gêneros quanto à renda, contudo os homens, em ambos segmentos sociais, estavam em uma situação de maior insegurança quanto à renda quando comparados às mulheres, em especial, por conta da maior ausência de suporte familiar entre os homens. Este grave quadro de ausência/insuficiência de renda, tanto dos homens, quanto das mulheres, em ambos os segmentos sociais, fez com que a manutenção das necessidades básicas destes requerentes ocorresse por meio do apoio de terceiros, familiares e de entidades religiosas, a fim de assegurarem o mínimo de alimentação, moradia, vestuário e medicamentos.

A maioria dos idosos (14) não recebe valores referentes ao Bolsa Família, apesar da situação de pobreza extrema identificada. Em relação às pessoas com deficiência, constatamos que a maioria dos entrevistados (11) também não recebe valores do programa. Este indicador do perfil dos requerentes revela a ausência de acesso de pessoas idosas e com deficiência a benefícios de combate à pobreza.

Destacamos que todas as mulheres do segmento social das pessoas com deficiência, que declararam ter acesso ao PBF, possuem filhos crianças ou 
adolescentes. Os valores recebidos variaram de $\mathrm{R} \$ 87,00$ a 117,00 . Por outro lado, observamos que os homens que relataram ter acesso ao Bolsa Família vivenciavam uma situação de extrema pobreza, com rendimentos familiares inferiores a $\mathrm{R} \$ 70,00$, independentemente, da existência de crianças, adolescentes ou gestantes no domicílio.

Em relação à qualidade de segurado do INSS, podemos ressaltar que todos os entrevistados homens, seja do segmento dos idosos, seja das pessoas com deficiência não possuíam a qualidade de segurado do INSS, assim como a maioria das mulheres idosas e todas as mulheres que requereram o benefício assistencial à pessoa com deficiência. Este dado mostra a ausência de proteção social da Previdência Social, porque apesar de não contribuírem para esta política, eles e elas possuem a qualidade de trabalhadores. A maioria dos requerentes (38) não atenderam ao critério contributivo da política de Previdência Social, apesar de todos(as) apresentarem trajetórias de trabalho e recorreram ao benefício assistencial para acessar renda, em virtude da idade avançada ou da condição de deficiência. A ausência da qualidade de segurado do INSS está relacionada com a ausência de contribuições para a política de Previdência Social. Com base na pesquisa realizada os principais motivos para que esses informantes não contribuíssem foram o desemprego, a renda insuficiente e a majoritária condição temporal de informalidade.

Apenas duas mulheres entre os quarenta entrevistados possuíam a qualidade de segurados do INSS, sendo uma mulher pertencente ao segmento das pessoas com deficiência cuja família manteve apenas uma contribuição para a Previdência Social, no intuito de acessar o auxílio-doença e outra mulher idosa que é pensionista do INSS.

Em resumo, podemos destacar que a caracterização do perfil socioeconômico dos requerentes do benefício de prestação continuada aponta para o envelhecimento e o processo de doença/deficiência dentro de um contexto de expressiva carência material e de pobreza. A inexistência e a insuficiência de renda foram contundentes nas colocações das dificuldades e privações materiais dos(as) requerentes. A baixa escolaridade dos(as) informantes também determinou o acesso a trabalhos mais precarizados e com baixos rendimentos. A ausência de proteção social por parte da previdência social atingiu a quase a totalidade dos requerentes, de ambos os segmentos sociais, exceto uma mulher idosa que se declarou pensionista do INSS.

No próximo item, nos deteremos sobre as condições de trabalho, gênero e as implicações destes aspectos nas possibilidades de acesso dos requerentes ao benefício assistencial. 


\section{3 - Gênero e trajetória de trabalho dos requerentes do BPC}

O eixo gênero e trajetória de trabalho dos requerentes do BPC buscou desenvolver reflexões sobre as particularidades das inserções dos(as) entrevistados(as) no âmbito do trabalho, a partir da perspectiva de gênero, permitindo identificar semelhanças entre homens e mulheres enquanto classe trabalhadora, assim como especificidades de gênero, com base na divisão sexual do trabalho e que compreendem processos contraditórios no acesso às políticas de previdência e assistência social.

O processo de desestruturação do mercado de trabalho, que ocorre no Brasil desde a década de 1990, está relacionado com os condicionantes próprios da economia internacional, sendo um deles a inserção subalterna e dependente do Brasil nesta esfera. Esta inserção subalterna condiciona as particularidades da reestruturação produtiva, da globalização e do neoliberalismo no país, acarretando o aumento do desemprego, da informalidade, da precariedade das condições e relações de trabalho. (Pochmann, 2008).

A pesquisa de campo revelou que tanto os homens quanto as mulheres, de ambos segmentos sociais, apresentaram características semelhantes em suas trajetórias de trabalho, especialmente, com a vivência de períodos de desemprego, de busca pela sobrevivência na informalidade e a atuação em funções de trabalho no setor de serviços. Contudo, há particularidades de gênero porque as entrevistadas permaneceram mais tempo desempregadas, apresentaram também maior tempo de trabalho na informalidade, exercendo funções com remunerações inferiores aos homens na informalidade, nas funções de faxineira e vendedoras de alimentos. Além destas funções, também exerciam papel central diante do trabalho reprodutivo, e quando este não era prestado diretamente pelas entrevistadas, era transferido para a mãe, avó, irmã ou vizinha, ou seja, sempre para uma figura feminina, exclusivamente.

Em relação aos homens e mulheres do segmento das pessoas com deficiência, os resultados revelaram que estes por conta da condição da doença/deficiência apresentaram o afastamento mais precoce da esfera do trabalho, sendo este um diferencial quando comparado às pessoas do segmento das pessoas idosas.

A trajetória de trabalho dos requerentes do benefício assistencial, de ambos os segmentos sociais, revelou que as funções exercidas por homens e mulheres são marcadas pela segmentação sexuada do mercado de trabalho, por 
espaços de atuação historicamente destinados às mulheres e aos homens, incluindo as diferenças nas remunerações que, geralmente, são maiores para os homens do que para as mulheres, mesmo no âmbito da informalidade. As principais funções exercidas pelas mulheres foram auxiliar de serviços gerais, manicure, empregada doméstica, cuidadora de idosos e crianças, caixa de supermercado, doceira e catadora de lixo. Os homens ocuparam as seguintes funções: auxiliar de serviços gerais, contínuo, frentista, porteiro, motorista, balconista, vendedor, mecânico, artesão, encarregado de obras e vendedor ambulante. Observem que as funções no setor de serviços se destacam, exigindo baixa escolaridade, mas com uma leve preponderância de atividades mais formalizadas.

A pesquisa revelou que os idosos homens e mulheres possuíam maior tempo de trabalho do que de contribuição e que nenhum deles (as) tinha alcançado o tempo mínimo de contribuição para a aposentadoria por idade que tem como requisito os 15 anos de contribuição. Identificamos que não alcançaram o tempo de contribuição exigido para ter acesso à aposentadoria, por conta dos longos períodos de desemprego que foram intercalados com inserções informais no mercado de trabalho, não possibilitando a continuidade das contribuições para a Previdência Social, na medida em que os rendimentos oriundos destes trabalhos eram insuficientes para manter as necessidades básicas.

Os dados revelaram que todas as mulheres idosas apresentaram tempo de trabalho. Contudo, metade delas não possuía nenhum tempo de contribuição para a Previdência Social e, entre essas, todo o tempo de trabalho foi desenvolvido na informalidade. Por seu turno, os homens idosos permaneceram mais tempo no trabalho formal e possuíam maior tempo de contribuição para a Previdência Social quando comparados às mulheres idosas. Ressaltamos que todos (10) os homens idosos apresentaram tempo de trabalho e de contribuição, diferentemente das idosas. Um aspecto da pesquisa de campo que merece ser mencionado foi a dificuldade que tivemos em localizar o quantitativo mínimo de homens idosos para a entrevista, uma vez que o benefício assistencial não é tão solicitado pelos homens vis-à-vis as mulheres.

De forma similar às mulheres idosas, todas as mulheres que requereram o benefício assistencial para a pessoa com deficiência também possuíam tempo de trabalho. A maioria apresentava tempo de contribuição para a Previdência Social e apenas duas (2) entrevistadas não apresentavam nenhum tempo de contribuição. Em relação aos homens, todos possuíam tempo de trabalho e exceto um não tinha nenhum tempo de contribuição.

As trajetórias de trabalho dos requerentes do segmento social das pessoas com deficiência foram marcadas por determinantes sociais semelhantes 
aos dos idosos, como, longos períodos de desemprego, concentrados em atividades informais em funções típicas do setor de serviços, com baixas remunerações e alta rotatividade. Um traço característico entre todos os grupos pesquisados foi a intermitência entre emprego e desemprego, a busca por renda para a sobrevivência material, por meio de atividades informais e sem rendimentos fixos. No entanto, destacamos que o processo de adoecimento/deficiência nesse segmento foi um elemento diferencial entre os grupos pesquisados, na medida em que determinou o afastamento mais precoce do mercado de trabalho.

Em relação às mulheres percebemos uma diferença, enquanto as mulheres que solicitaram o BPC para a pessoa com deficiência vivenciaram o processo de adoecimento precoce num contexto de profundas mudanças no mercado de trabalho, associado aos cuidados com filhos pequenos, as idosas experimentaram o adoecimento de forma mais tardia e um mercado de trabalho levemente diferenciado do quadro atual. Apesar desse cenário, as mulheres que declararam alguma deficiência possuem maior tempo de contribuição do que as mulheres idosas, especialmente, porque mantiveram uma trajetória de trabalho no âmbito formal de trabalho por mais tempo quando comparadas às mulheres idosas. Isso significa que as idosas permaneceram por mais tempo em trabalhos informais quando comparadas às mulheres com deficiência. Estas, por sua vez, afirmaram, em sua maioria, que o maior impedimento para a continuidade no mercado de trabalho formal não foi o trabalho doméstico e sim o processo de adoecimento/deficiência. Nossos dados revelaram que a existência de filhos pequenos não foi um entrave contundente para a manutenção do trabalho das mulheres com deficiência porque houve a transferência do cuidado das crianças para outras mulheres, como, avós, tias ou, ainda, para creches municipais e filantrópicas.

Quando comparadas aos homens de ambos os segmentos sociais, verificamos que as mulheres sofreram maiores constrangimentos na inserção e manutenção no mercado de trabalho por conta do trabalho reprodutivo. Observamos, ainda, que as mulheres do segmento das pessoas com deficiência contavam com redes sociais de apoio mais amplas no desenvolvimento do trabalho reprodutivo quando comparadas com as mulheres idosas, seja no que se refere ao trabalho do cuidado com as crianças, seja nas demais atividades do âmbito doméstico. Podemos inferir que a condição da doença/deficiência tem um peso importante posto que essas mulheres também demandavam cuidados específicos em saúde. Cabe registrar que a situação de doença/deficiência é um aspecto presente na vida dos homens e das mulheres dos dois segmentos sociais, tendo em vista a tendência de envelhecimento da população que agrega questões 
como o surgimento de doenças crônicas e deficiências de naturezas diversas como, físicas, mentais e sensoriais. Destacamos que as pessoas idosas entrevistadas, mesmo aquelas com 60 anos de idade, também apresentavam situações de doença/deficiência.

Como esperado, a questão do cuidado com os filhos pequenos e as demais atividades domésticas repercutiram com mais intensidade na trajetória de trabalho das mulheres do que dos homens. A pesquisa confirmou que o trabalho reprodutivo gerou impactos importantes na inserção e na permanência das mulheres no mercado de trabalho quando comparados aos homens entrevistados.

A maior parte das mulheres idosas (8) considerou que o trabalho reprodutivo interferiu em suas trajetórias de trabalho, especialmente, por conta das atividades domésticas e do cuidado com crianças, idosos e doentes. Porém, duas mulheres idosas afirmaram que o trabalho reprodutivo não interferiu em suas trajetórias de trabalho, uma vez que não tiveram filhos e que por isso mantinham uma rotina de trabalho, com autonomia.

Em relação às mulheres do segmento das pessoas com deficiência, é possível destacar que a metade (5) delas afirmou que trabalho reprodutivo não interferiu em suas trajetórias de trabalho, e sim o processo de adoecimento, a deficiência que surgiu precocemente e as precárias condições de vida. A outra metade (5) das mulheres afirmou que o trabalho reprodutivo interferiu em suas trajetórias de trabalho, especialmente, por causa dos filhos ainda crianças que demandavam atenção em tempo integral.

Todos os homens, independentemente do segmento social, declararam que o trabalho reprodutivo não interferiu em suas trajetórias de trabalho. Durante as entrevistas, esses idosos se referiam às mulheres como as responsáveis pelo trabalho reprodutivo, podendo ser as esposas, filhas ou irmãs.

A pesquisa revelou que a trajetória de trabalho dos requerentes do BPC apresentou duas tendências relevantes. De um lado, está relacionada com as transformações no mundo do trabalho, determinadas pela reestruturação produtiva, pela mundialização do Capital e pelo neoliberalismo, acarretando no desemprego estrutural, na cristalização da informalidade, nos baixos salários e nos contratos flexíveis de trabalho com perdas e limitações de direitos advindos do trabalho, afetando homens e mulheres enquanto pertencentes a classe trabalhadora. De outro lado, revelou que a centralidade da mulher no trabalho reprodutivo é um expressivo determinante na sua trajetória de trabalho repercutindo em formas mais contundentes de desemprego, no maior tempo de permanência na informalidade e em jornadas menores de trabalho. Tais características da 
condição feminina no trabalho provocaram remunerações inferiores aos homens, tanto no âmbito formal, quanto informal de trabalho.

\section{Considerações Finais}

Diante das reflexões apresentadas, consideramos que o BPC possui um expressivo significado social na sociedade brasileira, na medida em que representa um recurso a estes homens e mulheres que seguem sem a proteção social da Previdência Social. Contudo, somente o acesso à renda, via benefício assistencial, sem políticas sociais articuladas não possibilita o atendimento integral a esses usuários e nem mesmo afeta a desigualdade pretérita entre homens e mulheres no mercado de trabalho.

Apesar do avanço social que o benefício assistencial representa, temos que sinalizar que o critério de renda reflete uma condicionalidade restritiva ao acesso dessas pessoas ao benefício de ambos segmentos sociais pesquisados. $\mathrm{O}$ critério de idade de 65 anos para acesso ao benefício assistencial é outro condicionante restritivo e divergente com o Estatuto do Idoso que define pessoa idosa como aquela com 60 anos ou mais, por isso foi possível identificarmos na pesquisa de campo pessoas com idade de 60 anos ou mais requerendo o benefício assistencial para a pessoa com deficiência, pois ainda não tinham completado os 65 anos de idade.

Para nossos(as) informantes, esse benefício representa uma garantia do mínimo de moradia, alimentação e saúde, o que deixa claro a distância entre as garantias constitucionais e a realidade social, uma vez que serviços de saúde, segurança alimentar e habitação deveriam ser atendidos pelas demais políticas sociais. A pesquisa revelou a distância e a ausência de intersetorialidade entre as políticas de proteção social para esses idosos (as) e pessoas com deficiência, especialmente, quando identificamos que as famílias, as instituições religiosas e as entidades filantrópicas permanecem como apoios centrais de proteção social.

A análise dos dados revelou os limites impostos pelas transformações do mundo do trabalho nas trajetórias de trabalho desses requerentes e os desdobramentos desses limites no acesso aos direitos sociais até então garantidos pela Seguridade Social. As políticas de trabalho, previdência e assistência social não só se comunicam como se condicionam, afetando diretamente os(as) trabalhadores(as) em sua busca por sobrevivência em momentos de envelhecimento e doença/deficiência. A precariedade das condições de trabalho dos requerentes do benefício assistencial condicionou a inviabilidade do acesso aos benefícios 
previdenciários como aposentadoria e auxílio-doença, bem como forçou a busca pelo acesso à renda, por meio do benefício assistencial.

O resultado da pesquisa confirmou a hipótese inicial de que os requerentes do benefício assistencial possuíam uma trajetória de trabalho com a qualidade de trabalhadores, mas sem o tempo de contribuição para o acesso aos benefícios previdenciários. Por esse motivo, homens e mulheres idosos e com deficiência recorriam ao benefício assistencial para o acesso à renda.

As implicações deste cenário não atingem apenas o(a) trabalhador(a), mas também seus familiares, ainda mais quando envolve crianças e adolescentes dependentes desses(as) trabalhadores(as), uma vez que o benefício assistencial não gera direito à pensão por morte e nem a décimo terceiro salário, restringindo ainda mais o acesso aos direitos sociais. Por isso, reforçamos a necessidade do desenvolvimento de pesquisas que tratam das interlocuções entre as políticas de Seguridade Social, visando o aprofundamento de temas relevantes para o avanço das políticas sociais em tempos de regressões de direitos sociais no país.

A perspectiva de gênero se mostra fundamental no âmbito das políticas sociais, especialmente, pelas desigualdades de classe, raça e gênero na sociedade brasileira. A divisão sexual e racial do trabalho revela desigualdades em que as mulheres são mais absorvidas pelas demandas do trabalho reprodutivo do que os homens. Identificamos que as mulheres nos dois segmentos sociais estudados apresentaram menor tempo de trabalho e de contribuição quando comparadas aos homens, por conta das demandas do trabalho reprodutivo, fazendo com que essas mulheres recorressem mais às ocupações informais, de jornada parcial, vivenciando maior tempo de desemprego e com menores salários. Tais resultados indicam que a expressiva desigualdade de gênero no mercado de trabalho acarreta implicações de acesso aos benefícios previdenciários e assistenciais.

A constatação de que esses(as) requerentes são trabalhadores(as), porém, sem condições de se aposentar ou se afastar por benefício previdenciário de auxílio-doença, recorrendo ao benefício assistencial para acesso à renda, nos sinaliza que, para além das perdas dos direitos sociais com as transformações do mundo do trabalho, há o reforço do caráter de seguro social da política de Previdência Social que se sobrepõe ao de Seguridade Social, direcionando ao BPC uma crescente demanda de pessoas idosas e com deficiência com uma trajetória de trabalho, porém sem qualidade de segurado do INSS, pela ausência de contribuições previdenciárias.

Considerando que a política de assistência social e os princípios que sustentam o BPC tem como objetivo central o combate à pobreza de forma in- 
tersetorial, ou seja, associando o acesso à renda, via BPC, com outras políticas sociais como, habitação, saúde, educação, trabalho e renda, a fim de que o benefício assistencial não seja um fim em si mesmo é necessário o desenvolvimento de pesquisas sobre o tema visando aferir o impacto do benefício na vida dos requerentes. Ademais, as demandas relacionadas ao trabalho de homens e mulheres que afetam o seu acesso aos benefícios previdenciários e assistenciais devem ser contempladas por pesquisas que incorporem as dimensões de gênero e raça no acesso, utilização e cobertura das políticas sociais.

O debate sobre o trabalho feminino, entendido como trabalho produtivo mais trabalho reprodutivo, e o acesso aos benefícios previdenciários precisa ser aprofundado, principalmente na atual conjuntura, onde as reivindicações por especificidades femininas nas proposições de reforma previdenciária se concentraram na idade diferenciada e na aposentadoria da dona de casa, revelando o debate da mercantilização do trabalho doméstico versus a sua publicização na ampliação e universalização das políticas sociais, principalmente, aquelas mais afeitas ao trabalho reprodutivo. Tais políticas e programas poderiam garantir condições de maior igualdade de gênero no mercado de trabalho com repercussões importantes no acesso às políticas de previdência e assistência social.

\section{Referências}

\section{ANUÁRIO ESTATÍSTICO DA PREVIDÊNCIA SOCIAL, SECRETA- RIA DA PREVIDÊNCIA SOCIAL. Empresa de Tecnologia e Informação da Previdência Social, 2015, Brasília.}

ARAUJO, Angela Maria Carneiro e LOMBARDI, Maria Rosa. Trabalho informal, gênero e raça no Brasil do século XXI. Cadernos de pesquisa. v. 43, n 149, p. 452-477. maio/agosto 2013.

BANDEIRA, Lourdes Maria e PRETURLAN, Renata Barreto. As pesquisas sobre uso do tempo e a promoção de igualdade de gênero. In: FONTOURA, Natália e ARAÚJO, Clara (org.) Uso do tempo e gênero. Rio de Janeiro: UERJ, 2016, p. 43-60.

BRASIL. Constituição (1988). Constituição da República Federativa do Brasil. Brasília, DF: Senado Federal, 1988. 140 p.

BRUSCHINI, Maria Cristina. Trabalho e gênero no Brasil nos últimos dez anos. Cadernos de Pesquisa, v. 37, n. 132. p. 537-572. Set./Dez, 2007. 
CESIT/IE - UNICAMP - Centro de Estudos Sindicais e Economia do Trabalho. UNICAMP. São Paulo, 2017.

CONVENÇÃO SOBRE OS DIREITOS DAS PESSOAS COM DEFICIÊNCIA: Protocolo Facultativo à Convenção sobre os Direitos das Pessoas com Deficiência: Decreto Legislativo $n^{\circ} 186$, de 09 de julho de 2008: Decreto $\mathrm{n}^{\circ}$ 6.949, de 25 de agosto de 2009. $4^{a}$ Ed., rev. e atual. Brasília: Secretaria de Direitos Humanos, 2010. 100p.

EMENDA CONSTITUCIONAL N¹03, de 12/11/2019. Casa Civil. Presidência da República. Subchefia para assuntos jurídicos.

GAMA, Andréa de Souza. Trabalho, família e gênero - impactos dos direitos do trabalho e da educação infantil. São Paulo: Cortez, 2014.

HARVEY, David. Condição pós-moderna. 2. ed. São Paulo: Loyola, 1993. HIRATA, Helena. Reestruturação Produtiva, cidadania e gênero. In: COSTA, Ana Alice et al. Um debate crítico a partir do feminismo: reestruturação produtiva, reprodução e gênero. São Paulo: CUT. 2002.

HIRATA, Helena, KERGOAT Daniele. Novas configurações da divisão sexual do trabalho. Caderno de pesquisa, v. 37, n. 132, p. 595-609, set./dez. 2007.

IAMAMOTO, Marilda Vilella. Serviço Social em tempo de capital fetiche: capital financeiro, trabalho e questão social. São Paulo, Cortez, 2007.

PINHEIRO, Luana Simões. Determinantes da alocação de tempo em trabalho reprodutivo: uma revisão sobre os achados em pesquisas nacionais e internacionais. In: FONTOURA, Natália e ARAÚJO, Clara (org). Uso do tempo e gênero. Rio de Janeiro. UERJ. 2016, p. 61-100.

POCHMANN, Marcio. O emprego no desenvolvimento da nação. 1. ed. São Paulo: Boitempo, 2008. 
